Though the voting on the present occasion makes it seem unlikely that any different decision would have been reached, the air of having rushed a constitutional problem is unfortunate.

Some doctors in South Africa (and in Rhodesia) will regret the action taken by the council of the C.M.A. Many will be indifferent. On behalf of those caught up in a system they detest and are unable to escape from, the B.M.A. delegate at the meeting (Dr. Ronald Gibson) suggested that the exclusion of the Medical Association of South Africa would penalize doctors who might benefit from the link. Dr. A. M. Mamujee, of the Tanzanian Medical Association, did not agree. Other delegates too felt that the time had passed when the retention of a "bridge" could do any good. The desire to keep communications open, to find a satisfactory compromise, to join things despite a certain ambiguity rather than sever them in the clear light of logic is supposed to be traditional to the British way of life. But some hurts are felt to be too deep to palliate, and Dr. Mamujee as well as other delegates spoke from a direct experience that must command respect.

That racial discrimination forms a pattern right through life in South Africa in the policy of apartheid is unquestioned. What had to be the concern of the C.M.A.'s council was the extent to which the Medical Association of South Africa itself encourages or allows this degrading doctrine to exist in medical practice and education. Several delegates questioned the M.A.S.A.'s representative, and he rightly told them, firstly, that he was not there to answer for his government, and secondly that on at least some aspects of apartheid his association was engaged in a running battle with the government. But on the question of separate training schools for white and non-white medical students his defence was unacceptable to the meeting. The reply that Dr. Combrink did give on this question could be applied to many others that might present themselves to observers of the South African scene. In effect he was saying that if the government did not provide a separate medical school for non-white students it would provide none at all. The same might be true of the separate wards for white and non-white patients in the hospitals, the separate bottles of blood taken from white and non-white donors, the separate waiting-rooms, and so on. The M.A.S.A.'s argument is that to refuse to acquiesce in an evil system would result in bringing on a worse.

An association which includes most of its country's medical practitioners is an essential part of that country's society, economy, and character. Though it may include doctors of diverse political and social opinions, the chances are that many of its members are fairly typical citizens of their country. Certainly the Medical Association of South Africa, though it has no colour bar in its rules of membership and opposes the government on some applications of apartheid to medical men-such as differential salaries for white and non-white doctors-knows that if it challenged the policy of apartheid directly and advised its members not to be ruled by that policy in their professional practice, the association as such would not survive a day.

When Dr. Combrink explained how his association came to be in the Commonwealth Medical Association though his country was not in the British Commonwealth his extempore reply on what could be thought a knotty constitutional point included a reference to the common origin of the C.M.A.'s members in "the British School of Medicine." However the character of this School may be defined, its ethical traditions deserve to be noted. Of special relevance to this debate is

1 British Medical fournal, 1970, 3, 472. the British School's adherence to the World Medical Association's code of ethics, which is a modern revision of the Hippocratic tradition that has come down to us, and reads in part: "I will not permit considerations of religion, nationality, race, party politics, or social standing to intervene between my duty and my patient." That in every country the medical profession has its ethical problems-in some countries more acutely than in others-was evident from the discussion at a subsequent session of the meeting. The C.M.A. will be giving valuable guidance to its member associations if it can enable them to help doctors, in Great Britain as in other countries throughout the Commonwealth, to understand and live by the accepted ethical code. For if the C.M.A. is to grow by the accession of new member associations, as is greatly to be hoped, and is to be a source of strength to its members, its character will depend largely on the ethical traditions that it exemplifies and its members respect.

\section{Fat Embolism}

Post-traumatic fat embolism was first described by F. Zenker ${ }^{1}$ in 1862. It may be defined as the blockage of blood vesselsmainly the small arterioles and capillaries-by fat globules, which are fluid and deformable. There are two pathological types, pulmonary and systemic. The former may occur by itself, but the latter is always associated with pulmonary emboli.

Clinically significant fat embolism occurs in $1-2 \%$ of patients after fracture of long bones (usually the lower limb), and occasionally after severe trauma to soft tissue and bone operations. Recently there have been reports of cardiac arrest after the use of acrylic cement for bone prostheses, as, for example, by Dr. J. N. Powell and his colleagues in the B.M.J. of 8 August, page 326. Drs. G. A. Gresham and A. Kuczynski (22 August, page 465) have suggested that the possibility of fat embolism needs investigation, and $\mathrm{Mr}$. Nigel $\mathrm{H}$. Harris draws attention to it in our correspondence columns this week (page 523).

According to S. Sevitt ${ }^{2}$ the fat originates at the site of trauma, and fat globules will pass into the circulation through damaged veins and then to the lungs, usually within a few minutes of the injury. C. M. Evarts ${ }^{3}$ explains the mechanism on the basis of an alteration in the stability of the emulsion of blood lipids after injury of tissue. This view has received further support from M. O'Driscoll and F. J. Powell, ${ }^{4}$ who recorded lipaemia in 79 patients after trauma; it corresponded at its peak to the onset of fat embolism. Some fat is excreted in the urine, and some may pass into the sputum. Occlusion of the small blood vessels does not necessarily have a damaging effect because of the fluidity of the emboli and because the collateral blood supply is extensive at capillary level. The brain and myocardium are the most susceptible to ischaemic anoxia. By contrast, the effect on the lungs is relatively slight. A symptom which may be of diagnostic importance is the appearance of small haemorrhages in the skin, mucous membranes, and retina.

Pulmonary fat embolism is found at necropsy in over $90 \%$ of patients who die after a recent fracture. Sevitt's view is that even gross embolism in the lungs does not cause symptoms or death. ${ }^{2} \mathrm{He}$ considered that pulmonary symptoms and complications after trauma are due to the haemorrhages and oligaemia and, if clinical fat embolism is present, to its cerebral effects. But there is some experimental evidence to 
indicate that significant amounts of embolic fat do not collect in the brain and that the lungs are efficient filters for the emboli. If this view is accepted, how can the cerebral symptoms be explained? A. P. J. Ross ${ }^{5}$ has shown by means of arterial gas analysis that the most important effect of fat embolism is hypoxia. This in turn is responsible for the early cerebral signs such as restlessness, anxiety, and drowsiness and ultimately is the cause of death. His evidence suggests that the hypoxia is brought about by two mechanisms-namely, defective gas transfer across the alveolar-arteriolar membrane as the result of the severe degree of alveolar oedema, and the shunting of unoxygenated blood through the lungs.

Systemic fat embolism is a less common finding at necropsy. It causes symptoms and sometimes death from damage to the brain. The more severe the initial injury and the more extensive the pulmonary embolism, the more likely is systemic embolism to occur.

It is of diagnostic importance to recognize three main clinical types-a fulminating condition, a classical syndrome, and incomplete syndromes. The fulminating type is rarely diagnosed during life, partly because the symptoms are masked by the effect of injury itself (especially head injury) or anaesthesia, and partly because the possibility is not considered. A typical story is that a few hours after injury a previously conscious patient lapses into a coma. This may be associated with a hemiparesis, epileptiform attacks, and poor response to resuscitation such as blood transfusion. Petechial haemorrhages in the skin, conjunctival sacs, and fundi are rarely found, since the patient often dies before they appear; nevertheless they should be looked for.

The first symptoms of the classical syndrome develop 24 to 48 hours after injury. The onset is sudden, with pyrexia and tachycardia. Symptoms of cerebral damage follow, such as mental confusion, restlessness, delirium, drowsiness, and finally coma. It is important to appreciate that a general anaesthetic may mask the symptoms, and the presenting feature will then be failure to regain consciousness after the anaesthesia. Other neurological effects which may sometimes occur are convulsions, incontinence, changes in deep reflexes, and paralysis. Respiratory effects, which may occur simultaneously, are dyspnoea, cyanosis, cough, frothy sputum, which may be blood-stained, and moist sounds in the lungs. Tachycardia is frequently noted and is probably due to stimulation of vagal nerve endings in the lungs. Petechial haemorrhages appear on the second or third day and can be found over the front of the chest, neck, and shoulders. They also occur in the fundi and conjunctival sacs. Anaemia and urinary incontinence are fairly common.

The incomplete syndromes are characterized by a less severe course, in which some of the classical features are absent. Thus cerebral symptoms occur with pyrexia, tachycardia, and a petechial rash but no respiratory symptoms. In some the cerebral symptoms are absent, and in others the only evidence of fat embolism is the petechial rash.

Diagnosis largely depends on bearing in mind the possibility that fat embolism has occurred. In summary, the clinical features of importance are the mental changes progressing to

\footnotetext{
Zenker, F. A., Beiträge zur normalen und pathologischen Anatomie der

Lungen, p. 31. Dresden, Braunsdorf, 1862.
Sevitt, S., Fat Embolism. London, Butterworths, 1962.

3 Evarts, C. M., Fournal of the American Medical Association, 1965, 194, 899.

- Evarts, C. M., Fournal of the American Medical Association, 1965, 194, 899.

soss, A. P. J., Annals of the Royal College of Surgeons of England, 1970, 46, 159.

- Larson, A. G., Lancet, 1968, 2, 250.

Freeman, M. A. R., Lancet, 1962, 1, 1302.

Ashbaugh, D. G., and Petty, T. L., Surgery, Gynecology and Obstetrics, $1966,123,493$.
}

coma during the first 48 hours after injury, tachycardia, tachypnoea, and petechial haemorrhages. Looking for fat in the sputum and urine is unreliable. Worth-while investigations include a chest radiograph, which may show a typical "snowstorm" appearance, a rapidly falling haemoglobin and platelet count, an electrocardiograph, which may show evidence of right heart strain, and renal biopsy. Ross's work ${ }^{5}$ suggests that arterial blood-gas analysis is a useful aid for diagnostic and therapeutic purposes.

There are no specific measures for dealing with fat embolism, but it is of the utmost importance to correct the hypoxia as soon as possible if irreversible brain damage is to be avoided. If the patient is comatose a tracheostomy should be performed and respiration maintained after curarization by means of intermittent positive-pressure respiration with added oxygen. Accumulated frothy sputum must be promptly aspirated. Brain damage is minimized by inducing hypothermia, which reduces cerebral oxygen consumption by about a third. It may be achieved by cooling the surface of the patient's body, producing a temperature of $35^{\circ} \mathrm{C}$. $\left(95^{\circ} \mathrm{F}\right.$.). Improvement in the blood flow and perfusion of the tissues is achieved by giving low-molecular-weight dextran and a vasodilator such as phenoxybenzamine, which, by producing an $\alpha$-adrenergic blockade, relieves vasospasm, lowers the peripheral resistance, and improves cardiac function. ${ }^{6}$ There is evidence that clofibrate reduces lipaemia and the incidence of fat embolism after trauma. ${ }^{4}$ Prophylactic antibiotics are usually advised. Intravenous hydrocortisone is sometimes useful if the above measures fail; the object is to reduce the inflammatory oedema in the lungs and thus assist in the transfer of gases across the alveolar membrane. Intravenous heparin has been advocated,? but a serious disadvantage is that further ischaemia and tissue damage may result from haemorrhage at the site of arrested emboli. Intravenous alcohol ${ }^{8}$ has not proved to be effective.

Until recently the prognosis for all patients in coma was thought to be poor, the assumption being that cerebral fat embolism was responsible for it. The recent work of Ross ${ }^{5}$ suggests that if we direct our attention energetically to the correction of hypoxia more of these patients will survive. Clearly prompt therapy depends on early diagnosis. In this respect it is too late to wait for the classical petechiae to appear; and most reliance must be placed on a history of mental confusion and restlessness progressing to coma. It is worth repeating that to be alert to the possibility of fat embolism occurring during the first 48 hours is a great help towards early diagnosis.

\section{Barring Rabies}

Hitherto no vaccine has been considered in Great Britain to be suitable for controlling the spread of rabies from animals. A proposal by the Committee of Inquiry on Rabies, therefore, that imported cats and dogs should be vaccinated against the disease as well as kept in quarantine is a considerable novelty in this country. Its interim report, ${ }^{1}$ published last week, recommends lifting the present total ban on susceptible animals and proposes arrangements for quarantine together with vaccination for the future.

Two considerations in particular have weighed with the committee. The first is that modern inactivated vaccines made

\footnotetext{
1 Committee of Inquiry on Rabies, Interim Report, Cmnd. 4457. London, H.M.S.O., 1970. 